\title{
Synthesis, Biophysical Characterization and in Vitro Transfection Activity of Novel Bivalent Amine Cationic Lipids in the Absence of Dioleoylphosphatidylethanolamine (DOPE)
}

\author{
Addai-Mensah Donkor ${ }^{1,2}$, Micheal Spelios', Michalakis Savva1 ${ }^{*}$ \\ ${ }^{1}$ Division of Pharmaceutical Sciences, Arnold \& Marie Schwartz College of Pharmacy and Health Sciences, Long \\ Island University, New York, USA \\ ${ }^{2}$ Faculty of Applied Sciences, Department of Applied Chemistry and Biochemistry, University for Development \\ Studies, Navrongo Campus, Upper East Region, Ghana \\ Email: ${ }^{*}$ adaddaimensah@gmail.com, ”addaidonkor@aol.com
}

Received 16 August 2014; revised 15 September 2014; accepted 10 October 2014

Copyright $@ 2014$ by authors and Scientific Research Publishing Inc.

This work is licensed under the Creative Commons Attribution International License (CC BY). http://creativecommons.org/licenses/by/4.0/

(c) (i) Open Access

\section{Abstract}

In this paper, a novel series of bis [(aminoethyl)]-amine cationic lipid derivatives have been synthesized and identified to purity by NMR and Elemental analysis. B16-F0 cells were transfected with cationic lipid/pEGFP-N1 and cationic lipid/ $\beta$-gal lipoplexes complexed at $+/-$ charge ratios of 1:1, 2:1, and 4:1. Dimyristoyl derivative showed highest activity at charge ratio 2:1 and both dimyristoyl and dioleoyl derivatives showed similar $\beta$-gal activity at charge ratios $4: 1$. In $40 \mathrm{mM}$ tris buffer $\mathrm{pH}$ 7.2 the dioleoyl derivative was able to fully complex with and retard pDNA at charge ratios above 2:1. None of the other lipid derivatives, dilauroyl, dimyristoyl, dipalmitoyl and distearoyl were able to fully neutralize the plasmid DNA at charge ratios similar to those used in the transfection experiment. The gel-to-liquid phase transition temperatures for dimyristoyl, dipalmitoyl and distearoyl were determined by a fluorescence anisotropy method to be $27.5^{\circ} \mathrm{C}, 32.5^{\circ} \mathrm{C}$ and $39^{\circ} \mathrm{C}$, respectively. A gel-to-liquid crystalline phase transition temperature below $37^{\circ} \mathrm{C}$, appears to be the crucial property that cationic lipids have to possess in order to mediate high levels of in vitro transfection activity in the absence of other helper lipids.

\section{Keywords}

Gene Delivery, Cationic Lipid, Acyl Chain Fluidity, Elasticity, Lipoplex, Transfection, Non-Viral

${ }^{*}$ Corresponding author.

How to cite this paper: Donkor, A.-M., Spelios, M. and Savva, M. (2014) Synthesis, Biophysical Characterization and in Vitro Transfection Activity of Novel Bivalent Amine Cationic Lipids in the Absence of Dioleoylphosphatidylethanolamine (DOPE). Pharmacology \& Pharmacy, 5, 1015-1028. http://dx.doi.org/10.4236/pp.2014.511113 


\section{Vector, DOPE, Endosomal Release, TNS}

\section{Introduction}

Cationic lipid-mediated gene transfer is one of the most promising non-viral gene delivery systems to date due to such characteristics as non-immunogenicity, efficacy, moderate toxicity and simplicity of large scale production and use. Cationic lipid-based nonviral gene delivery system is therefore an attractive approach for therapeutic gene transfer [1]. Most cationic lipids have three parts: 1) a hydrophobic lipid anchor group; 2) linker group, such as an ester, amide, or carbamate, and 3) a positively charged headgroup, which interacts with pDNA, leading to its condensation [2] [3]. Among all the basic components of the cationic lipid, the type of head group has been made known to have a dominant role in transfection efficiency and toxicity. Three useful properties typify the activity of any cationic liposome formulation: 1) efficient DNA condensation; 2) increased cellular uptake due to interaction of positively charged complexes with negatively charged biological surfaces; and 3) membrane fusion or transient membrane destabilization with the plasma membrane or the endosome to accomplish delivery into the cytoplasm while avoiding degradation in the lysosomal compartment [4].

Ever since the introduction of the transfection reagent Lipofectin, a 1:1 w/w mixture of the cationic lipid $N$-[1-(2,3-dioleoyloxy)propyl]- $N, N, N$-trimethylammonium (DOTMA) and dioleoyl phosphatidyl ethanolamine (DOPE) [5] [6], many cationic lipids bearing either a single tertiary or quaternary ammonium headgroup or protonatable polyamines linked to dialkyl or cholesterol anchors, have been designed for in vitro transfection of a variety of cell types [7] [8]. Commercially available cationic lipids used as liposome formulations or alone for gene delivery consist of DOTMA; 2,3-dioleyloxy- $N$-[2-spermine carboxamide] ethyl- $N, N$-dimethyl-1-propanammonium trifluoroacetate (DOSPA), 1,2-bis(oleoyloxy)-3-(trimethylammonio)propane (DOTAP), $N$-[1-(2,3dimyristyloxy)propyl]- $N, N$-dimethyl- $N$-(2-hydroxyethyl) ammonium bromide (DMRIE), $3 \beta$-[ $N$ - $\left(N^{\prime}, N^{\prime}\right.$-dimethylaminoethane) carbamoyl]cholesterol (DC-Chol), and dioctadecyl amidoglyceryl spermine (DOGS, Transfectam). A few such compounds have also been used in initial clinical studies [9]. Nonetheless, many of the cationic lipids used in early clinical trials such as DC-Chol, DMRIE, and GL-67, although effective in vitro, have proven inefficient in vivo, especially when compared with viral vectors.

To this end, a new series of novel cationic lipid derivatives containing bis[(aminoethyl)]-amine headgroup at the 2-position and hydrophobic chains at the 1- and 3-position, have been synthesized by acylation of a 1,3-diamino-2-propanol backbone using, dilauroyl, dimyristoyl, dipalmitoyl, distearoyl and dioleoyl acyl chlorides. The fatty acyl chains were linked to the polar cationic head group via amide bonds that are degradable but considerably more stable than the easily hydrolyzed ester bond found in phospholipids. Our aim is to correlate the physicochemical and biophysical properties of cationic lipids with their interaction with plasmid DNA and their transfection efficiency in tissue culture. Correlation of the cationic lipids properties associated with high transfection activity will inevitably help design new lipids with enhanced transfection activity.

\section{Materials and Methods}

\subsection{Materials}

1,3-Diaminopropanol 95\%, myristoyl chloride 98\%, palmitoyl chloride 98\%, lauroyl chloride 98\%, oleoyl chloride technical grade ( 85\%), stearoyl 99\%, p-nitrophenyl chloroformate 97\%, diethylenetriamine 99\%, benzyl chloroformate 95\%, N-(2-aminoethyl)ethane-1,2-diamine 99\%, palladium (II) chloride 99.9+\%, 10\% palladium on activated carbon, triethylsilane 97\%, tris $\mathrm{HCl}$ (99.8+\%), ninhydrin, 2-(p-toluidino)-6-naphthalenesulfonic acid (TNS), 3-(4,5-dimethylthiazol-2-yl)-2,5-diphenyl tetrazolium bromide (MTT) and o-nitrophenyl- $\beta$-D-galactopyranoside and anhydrous tetrahydrofuran (THF) were purchased from Sigma-Aldrich (St. Louis, MO). Agarose, ethidium bromide, RPMI medium, fetal bovine serum, combined penicillin-streptomycin aqueous solution $(10,000 \mathrm{U} / \mathrm{mL}$ and $10,000 \mu \mathrm{g} / \mathrm{mL}$, respectively), sodium pyruvate and trypsin-EDTA were from Invitrogen Life Technologies (Carlsbad, CA). Water for buffer preparation was obtained from a Barnstead NANOpure ultrapure water system (Barnstead, Dubuque, IA).

\subsection{Synthesis}

Dibenzyl (iminodiethane-2,1-diyl)biscarbamate (3). N-(2-aminoethyl)ethane-1,2-diamine, 1 (49.5 mmol, 5.2 
$\mathrm{mL}$ ) was placed in a cleaned, dry, three-neck reaction flask and 2.1 mol equivalent of sodium hydroxide (4.07 g, $101.75 \mathrm{mmol}$ ) in $50 \mathrm{~mL}$ of distilled water was added to a separatory funnel. Benzyl chloroformate 2 (18.1 g, $106.2 \mathrm{mmol}$ ) was added to another separatory funnel and the reaction flask was cooled on ice-bath. About two drops of benzyl chloroformate and five drops of sodium hydroxide solution were added simultaneously to [bis(2-aminoethyl)]-amine in the reaction flask and after addition was complete, the reaction mixture was stirred at room temperature for one hour. Distilled water, $100 \mathrm{~mL}$ were added to the mixture and the product was extracted three times with $200 \mathrm{~mL}$ ethyl acetate, dried with $\mathrm{MgSO}_{4}$ and the ethyl acetate layers were combined and evaporated under reduced pressure to give compound 3 (Scheme 1). The material was applied on silica gel and eluted with $1 \% \mathrm{MeOH} / \mathrm{CHCl}_{3}$ to afford a pale gum at room temperature (14.8 g, 81\%), which crystallized into a whitish powder at $4^{\circ} \mathrm{C}$. The product was identified by iodine vapor, $R_{f}=0.25(1: 4 \mathrm{v} / \mathrm{v}$ methanol/chloroform), while ninhydrin staining on TLC chromatogram yielded no color, indicating complete protection of the primary amine groups (Scheme 1). ${ }^{1} \mathrm{H}$ NMR $\left(400 \mathrm{MHz}, \mathrm{CDCl}_{3}, 20^{\circ} \mathrm{C}\right.$, TMS) $\delta 3.24-3.40\left(\mathrm{~m}, 8 \mathrm{H}, \mathrm{OCONHCH}_{2} \mathrm{CH}_{2}\right.$ ), 5.02 (s, $4 \mathrm{H}, \mathrm{C}_{6} \mathrm{H}_{5} \mathrm{CH}_{2}$ ), 5.32 (sb, 2H, HNC (O) O), 7.33 (s, 10H, $\mathrm{C}_{6} \mathrm{H}_{5}$ ).

$\mathbf{N}, \mathbf{N}^{\prime}$-dilauroyl-1,3-diaminopropan-2-ol (5). The procedure was similar to that described elsewhere [10] [11]. Briefly, 1,3-diamino-2-hydroxypropane $4(1.35 \mathrm{~g}, 15 \mathrm{mmol})$ was added in $300 \mathrm{~mL}$ anhydrous tetrahydrofuran in a clean dry two-necked reaction flask and the mixture was stirred continuously for one hour until it dissolved. Freshly distilled triethylamine $(5 \mathrm{~mL}, 36 \mathrm{mmol})$ was added dropwise and the reaction mixture was stirred for an additional fifteen minutes. Lauroyl chloride $(6.6 \mathrm{~mL}, 30 \mathrm{mmol})$ was dissolved in a minimum amount of THF and added dropwise to the reaction flask for a period of thirty minutes and the reaction was stirred for ten more minutes after which THF was removed by suction filtration. The crude product was treated with $150 \mathrm{~mL}$ distilled water and $350 \mathrm{~mL}$ cold THF on ice-bath for 30 minutes with constant stirring and the mixture was suction filtered. The precipitate was washed several times with ethyl ether, dried in a vacuum oven at $60^{\circ} \mathrm{C}$ for one hour and further air dried overnight. The product was re-crystallized using chloroform/ether to afford a light yellowish powder (5.88 g, 86\%) of compound 5 (Scheme 2). ${ }^{1} \mathrm{H}$ NMR $\left(400 \mathrm{MHz}, \mathrm{CDCl}_{3}, 20^{\circ} \mathrm{C}\right.$, TMS) $\delta 0.82-0.85$ (t, 6H, $\left.\mathrm{CH}_{3}\right) .1 .21$ - 1.26 (coherent peak, 32H, 8( $\left.\mathrm{CH}_{2}\right)_{2}, 1.61$ (sb, $4 \mathrm{H}, \mathrm{CH}_{2} \mathrm{CH}_{2} \mathrm{CO}$ ), 2.21 (t, $4 \mathrm{H}, \mathrm{CH}_{2} \mathrm{CO}$ ), 3.18 3.44 (m, 4H, $\left.\mathrm{CH}_{2} \mathrm{NH}\right), 3.74$ (m, $\left.1 \mathrm{H}, \mathrm{CH}\right), 6.25$ (m, 2H, HNCO).

N,N'-dilauroyl-1,3-diaminopropan-2-(p-nitrophenyl)carbonate (10). Compound 5 (2.5 g, 5.5 mmol) was dissolved in anhydrous THF $(200 \mathrm{~mL})$ and heated on oil-bath to approximately $60^{\circ} \mathrm{C}$. Para nitrophenyl chloroformate ( $6 \mathrm{mmol}, 1.2 \mathrm{~g}$ ) was dissolved in $10 \mathrm{~mL}$ THF and added dropwise to the solution, followed by dropwise addition of pyridine $(1.2 \mathrm{mmol}, 50 \mu \mathrm{L})$ to the reaction mixture. The mixture was stirred for $2-3$ hours on oilbath and additional p-nitrophenyl chloroformate $(10.8 \mathrm{mmol}, 2.1 \mathrm{~g})$ and pyridine $(1.2 \mathrm{mmol}, 50 \mu \mathrm{L})$ were added with continuous stirring for three more hours. The mixture was then cooled to room temperature and suction filtered to remove pyridine hydrochloride. The filtrate was subsequently collected and the solvent was removed under reduced pressure on rotary evaporator to afford a pale yellowish residue. The residue was dissolved in 150<smiles>O=C(Cl)OCc1ccccc1</smiles>

1<smiles>NCCNCCN</smiles>

2<smiles>CCCCCC(C)NCCNC(=O)OCc1ccccc1</smiles>

3

Scheme 1. Synthetic procedure for the preparation of Dibenzyl (iminodiethane-2,1-diyl)biscarbamate 3. 
<smiles>[R]C(=O)NCC(CNC([R])=O)OC(=O)Oc1ccc([N+](=O)[O-])cc1</smiles>

4
10-14<smiles>[R]C(=O)NCC(CNC([R])=O)OC(=O)N(CCNC(=O)OCc1ccccc1)CCNC(=O)OCc1ccccc1</smiles>

15-18, 19

d<smiles>CC(C)C</smiles><smiles>[R]C(=O)NCC(CNC([R])=O)OC(=O)N(CCN)CCN</smiles>

\section{0-24}

Scheme 2. Synthetic procedure for the preparation of 1,3-dialkoylamidopropane-based lipids 20-24. (a) anhy. THF, RCOCl, $\mathrm{Et}_{3} \mathrm{~N}$, rt (b) anh. THF, p-nitrophenyl chlorocarbonate, pyridine, $60^{\circ} \mathrm{C} 2 \mathrm{~h}$, rt 3 h (c) THF 3, Et ${ }_{3} \mathrm{~N}$, rt 3 h (d) $\mathrm{H}_{2} / \mathrm{Pd} / \mathrm{C}$, rt 12 h (e) anhy. $\mathrm{CHCl}_{3}, \mathrm{PdCl}_{2},\left(\mathrm{C}_{2} \mathrm{H}_{5}\right)_{3} \mathrm{SiH}$, $\mathrm{Et}_{3} \mathrm{~N}$, reflux 3 h. Analogs 5, 10, 15, 20; 6, 11, 16, 21; 7, 12, 17, 22; 8, 13, 18, 23 and 9, 14, 19, 24 correspond to $\mathrm{R}=\mathrm{C}_{11} \mathrm{H}_{23}, \mathrm{C}_{13} \mathrm{H}_{27}, \mathrm{C}_{15} \mathrm{H}_{31}, \mathrm{C}_{17} \mathrm{H}_{35}$ and $\mathrm{C}_{17} \mathrm{H}_{33}$, respectively.

$\mathrm{mL}$ chloroform, transferred into a separatory funnel and washed with $0.25 \mathrm{~N}$ hydrochloric acid. The organic layer was collected, combined and the solvent removed under reduced pressure after which the material was chromatographed on silica gel starting with $1 \%$ methanol/chloroform. The product was eluted with $1 \%$ - 3\% methanol/chloroform and the solvent was removed under reduced pressure to afford a light yellowish oily product (3.16 g, 93\%), one spot, $R_{f}=0.35$ (10\% methanol/chloroform). ${ }^{1} \mathrm{H}$ NMR (400 MHz, $\mathrm{CDCl}_{3}, 20^{\circ} \mathrm{C}, \mathrm{TMS} \delta$ 0.91 - 0.94 (t, 6H, $\left.\mathrm{CH}_{3}\right), 1.26$ - 1.30 (coherent peak, 32H, 8( $\left.\left.\mathrm{CH}_{2}\right)_{2}\right), 1.62\left(\mathrm{~m}, 4 \mathrm{H}, \mathrm{CH}_{2} \mathrm{CH}_{2} \mathrm{CO}\right), 2.24(\mathrm{t}, 4 \mathrm{H}$, $\mathrm{CH}_{2} \mathrm{CO}$ ), 3.42 - $3.68\left(\mathrm{~m}, 4 \mathrm{H}, \mathrm{CH}_{2} \mathrm{~N}\right), 4.78(\mathrm{~m}, 1 \mathrm{H}, \mathrm{CH}), 6.46$ (t, 2H, HNCO), 7.36 - 7.39, 8.43 - 8.46 (two d, 4H, $\left.\mathrm{C}_{6} \mathrm{H}_{4}\right)$. 
Dibenzyl \{[(N, N'-dilauroyl-1, 3-diaminopropyl-2-oxycarbonyl) imino] diethane-2, 1-diyl $\}$ biscarbamate (15). Compound 10 (1.8 g, $2.9 \mathrm{mmol})$ was dissolved in $100 \mathrm{~mL}$ anhydrous THF and compound 3 (1.2 g, 3.2 mmol) was added to the mixture at room temperature followed by dropwise addition of triethylamine $(1.25 \mathrm{~mL}$, $6.2 \mathrm{mmol}$ ). The reaction mixture was stirred at room temperature for three hours and THF was removed under reduced pressure. The residue was dissolved in chloroform, transferred to a separatory funnel, washed with saturated brine, further washed with saturated sodium bicarbonate and dried with anhydrous $\mathrm{MgSO}_{4}$. The organic layers were collected, condensed under reduced pressure and the product was purified on silica gel $(5 \%-20 \%$ methanol/chloroform). The fractions were collected and concentrated on rotary evaporator to give a light yellowish oil compound 15 (1.93 g, 81\%). $R_{f}=0.42$ (10\% methanol/chloroform), $\mathrm{C}_{48} \mathrm{H}_{77} \mathrm{~N}_{5} \mathrm{O}_{8}$ (MW 852): MS (Positive/Negative ES) $\mathrm{m} / \mathrm{z} 859.3$ [M + Li]. ${ }^{1} \mathrm{H}$ NMR $\left(400 \mathrm{MHz}, \mathrm{CDCl}_{3}, 20^{\circ} \mathrm{C}\right.$, TMS) $\delta 0.63$ (t, $6 \mathrm{H}, \mathrm{CH}_{3}$ ), 1.00 (coherent peak, 32H, 8( $\left.\mathrm{CH}_{2}\right)_{2}$ ), 1.40 (sb, $\left.4 \mathrm{H}, \mathrm{CH}_{2} \mathrm{CH}_{2} \mathrm{CO}\right), 2.00\left(\mathrm{t}, 4 \mathrm{H}, \mathrm{CH}_{2} \mathrm{CO}\right), 3.07$ - $3.38\left(\mathrm{~m}, 12 \mathrm{H}, \mathrm{CH}_{2} \mathrm{NHCO}\right.$, OCONHCH $\mathrm{CH}_{2}$ ), $4.74(\mathrm{~m}, 1 \mathrm{H}, \mathrm{CH}), 5.81$ (s, $4 \mathrm{H}, \mathrm{C}_{6} \mathrm{H}_{5} \mathrm{CH}_{2}$ ), 5.18 (sb, $\left.2 \mathrm{H}, \mathrm{HNC}(\mathrm{O}) \mathrm{O}\right), 6.20$ (m, $2 \mathrm{H}, \mathrm{HNCO}$ ), 7.08 (coherent peak, $10 \mathrm{H}, \mathrm{C}_{6} \mathrm{H}_{5}$ ).

The remaining intermediate derivatives 16-19 were synthesized applying similar procedures.

Dibenzyl \{[(N, N'-dimyristoyl-1, 3-diaminopropyl-2-oxycarbonyl) imino] diethane-2- 1-diyl $\}$ biscarbamate (16). Yield 60\%, $R_{f}=0.42$ (10\% methanol/chloroform). $\mathrm{C}_{52} \mathrm{H}_{87} \mathrm{~N}_{5} \mathrm{O}_{8}$ (MW 922): MS (Positive/Negative ES) $\mathrm{m} / \mathrm{z}$ 929.4 [M + Li] , ${ }^{1} \mathrm{H}$ NMR $\left(400 \mathrm{MHz}, \mathrm{CDCl}_{3}, 20^{\circ} \mathrm{C}\right.$, TMS) $\delta 0.92\left(\mathrm{t}, 6 \mathrm{H}, \mathrm{CH}_{3}\right), 1.21-1.25$ (coherent peak, 40H, $\left.10\left(\mathrm{CH}_{2}\right)_{2}\right)$ ), $1.55\left(\mathrm{~m}, 4 \mathrm{H}, \mathrm{CH}_{2} \mathrm{CH}_{2} \mathrm{CO}\right), 2.18\left(\mathrm{~m}, 8 \mathrm{H}, \mathrm{CH}_{2} \mathrm{CO}, \mathrm{CH}_{2} \mathrm{NH}_{2}\right), 3.24-3.69(\mathrm{~m}, 8 \mathrm{H}$, $\left.\mathrm{CH}_{2} \mathrm{NHCO}, \mathrm{OCON}\left(\mathrm{CH}_{2}\right)_{2}\right), 4.74(\mathrm{~m}, 1 \mathrm{H}, \mathrm{CH}), 5.81\left(\mathrm{~s}, 4 \mathrm{H}, \mathrm{C}_{6} \mathrm{H}_{5} \mathrm{CH}_{2}\right), 4.76\left(\mathrm{~m}, 1 \mathrm{H},\left(\mathrm{CH}_{2}\right)_{2} \mathrm{CHOCO}\right), 6.36(\mathrm{~m}$, 2H, HNCO), 7.08 (coherent peak, $10 \mathrm{H}, \mathrm{C}_{6} \mathrm{H}_{5}$ ).

Dibenzyl \{[(N, N'-dipalmitoyl-1, 3-diaminopropyl-2-oxycarbonyl) imino] diethane-2, 1-diyl\} biscarbamate (17). Yield 64\%, $R_{f}=0.41$ (10\% methanol/chloroform). $\mathrm{C}_{57} \mathrm{H}_{95} \mathrm{~N}_{5} \mathrm{O}_{8}$ (MW 978): MS (Positive/Negative ES) $\mathrm{m} / \mathrm{z} 985.5[\mathrm{M}+\mathrm{Li}] .{ }^{1} \mathrm{H}$ NMR (400 MHz, $\mathrm{CDCl}_{3}, 20^{\circ} \mathrm{C}$, TMS) $\delta 0.87-0.90\left(\mathrm{t}, 6 \mathrm{H}, \mathrm{CH}_{3}\right), 1.26-1.30$ (coherent peak, 48H, 12( $\left.\mathrm{CH}_{2}\right)_{2}$ ), $1.60\left(\mathrm{~m}, 4 \mathrm{H}, \mathrm{CH}_{2} \mathrm{CH}_{2} \mathrm{CO}\right), 2.18\left(\mathrm{~m}, 8 \mathrm{H}, \mathrm{CH}_{2} \mathrm{CO}, \mathrm{CH}_{2} \mathrm{NH}_{2}\right), 3.30$ - 3.70 (m, 8H, $\mathrm{CH}_{2} \mathrm{NHCO}$, OCON $\left.\left(\mathrm{CH}_{2}\right)_{2}\right), 4.74\left(\mathrm{~m}, 1 \mathrm{H},\left(\mathrm{CH}_{2}\right)_{2} \mathrm{CHOCO}\right), 5.81$ (s, $\left.4 \mathrm{H}, \mathrm{C}_{6} \mathrm{H}_{5} \mathrm{CH}_{2}\right), 6.42(\mathrm{~m}, 2 \mathrm{H}, \mathrm{HNCO}), 7.08$ (coherent peak, $10 \mathrm{H}, \mathrm{C}_{6} \mathrm{H}_{5}$ ).

Dibenzyl \{[(N, N'-distearoyl-1, 3-diaminopropyl-2-oxycarbonyl) imino] diethane-2, 1-diyl\} biscarbamate (18). Yield 52\%, $R_{f}=0.35$ (10\% methanol/chloroform). $\mathrm{C}_{61} \mathrm{H}_{103} \mathrm{~N}_{5} \mathrm{O}_{8}$ (MW 1034): MS (Positive/Negative ES) $\mathrm{m} / \mathrm{z} 1041.5[\mathrm{M}+\mathrm{Li}] .{ }^{1} \mathrm{H}$ NMR $\left(400 \mathrm{MHz}, \mathrm{CDCl}_{3}, 20^{\circ} \mathrm{C}\right.$, TMS) $\delta 0.84\left(\mathrm{t}, 6 \mathrm{H}, \mathrm{CH}_{3}\right), 1.21-1.25$ (coherent peak, 56H, 14( $\left(\mathrm{CH}_{2}\right)_{2}$ ), $1.56\left(\mathrm{~m}, 4 \mathrm{H}, \mathrm{CH}_{2} \mathrm{CH}_{2} \mathrm{CO}\right), 2.19\left(\mathrm{~m}, 8 \mathrm{H}, \mathrm{CH}_{2} \mathrm{CO}, \mathrm{CH}_{2} \mathrm{NH}_{2}\right), 3.40-3.74(\mathrm{~m}, 8 \mathrm{H}$, $\mathrm{CH}_{2} \mathrm{NHCO}$ OCON $\left.\left(\mathrm{CH}_{2}\right)_{2}\right)$, 4.75 (m, $1 \mathrm{H},\left(\mathrm{CH}_{2}\right)_{2} \mathrm{CHOCO}$ ), 5.81 (s, $\left.4 \mathrm{H}, \mathrm{C}_{6} \mathrm{H}_{5} \mathrm{CH}_{2}\right), 6.22$ (m, 2H, HNCO), 7.08 (coherent peak, $10 \mathrm{H}, \mathrm{C}_{6} \mathrm{H}_{5}$ ).

Dibenzyl \{[(N, N'-dioleoyl-1, 3-diaminopropyl-2-oxycarbonyl) imino] diethane-2, 1-diyl\} biscarbamate (19). Yield 40\%, $R_{f}=0.39$ (10\% methanol/chloroform). $\mathrm{C}_{61} \mathrm{H}_{99} \mathrm{~N}_{5} \mathrm{O}_{8}$ (MW 1030), MS (Positive/Negative ES) $\mathrm{m} / \mathrm{z} 1038.477[\mathrm{M}+\mathrm{Li}]{ }^{1} \mathrm{H}$ NMR $\left(400 \mathrm{MHz}, \mathrm{CDCl}_{3}, 20^{\circ} \mathrm{C}\right.$, TMS) $\delta 0.86$ (t, $\left.6 \mathrm{H}, \mathrm{CH}_{3}\right), 1.24$ - 1.28 (coherent peak, 40H, 10( $\left.\left.\mathrm{CH}_{2}\right)_{2}\right), 1.62$ (m, 4H, $\mathrm{CH}_{2} \mathrm{CH}_{2} \mathrm{CO}$,), $1.96-2.25$ (m, $16 \mathrm{H}, \mathrm{CH}_{2} \mathrm{CH}=\mathrm{CHCH}_{2} ; \mathrm{CH}_{2} \mathrm{CO}, \mathrm{CH}_{2} \mathrm{NH}_{2}$ ), 3.20 $3.54\left(\mathrm{~m}, 8 \mathrm{H}, \mathrm{CH}_{2} \mathrm{NHCO}, \mathrm{OCON}\left(\mathrm{CH}_{2}\right)_{2}\right), 4.75(\mathrm{~m}, 1 \mathrm{H}),, 4.74\left(\mathrm{~m}, 1 \mathrm{H},\left(\mathrm{CH}_{2}\right)_{2} \mathrm{CHOCO}\right), 5.30(\mathrm{~m}, 4 \mathrm{H}, \mathrm{CH}=\mathrm{CH})$, 5.81 (s, 4H, $\left.\mathrm{C}_{6} \mathrm{H}_{5} \mathrm{CH}_{2}\right) 6.24$ (m, 2H, HNCO), 7.08 (coherent peak, 10H, $\mathrm{C}_{6} \mathrm{H}_{5}$ ).

N, N'-dilauroyl-1,3-diaminopropyl-2-[bis-(2-aminoethyl)] carbamate (20, LDVAD). Compound 15 (1.5 g, $1.8 \mathrm{mmol}$ ) was dissolved in $200 \mathrm{~mL}$ of anhydrous THF in a Parr hydrogenation bottle. Approximately $3 \mathrm{~mL}$ of glacial acetic acid and about $800 \mathrm{mg}$ of $10 \% \mathrm{Pd} / \mathrm{C}$ catalyst were added and the reaction mixture was stirred continuously overnight. The excess acid was neutralized with sodium bicarbonate solution, and the mixture was filtered under vacuum through celite on a Buchner funnel to remove the catalyst. After removing the organic solvent under reduced pressure, the crude product was partitioned between chloroform and saturated sodium bicarbonate and the organic layer was washed several times with saturated brine. The organic phase was transferred into an Erlenmeyer flask, dried with $\mathrm{MgSO}_{4}$ and the solvent was removed under reduced pressure. The crude was loaded on silica gel and product $20(0.9 \mathrm{~g}, 85 \%)$ was eluted with $10 \%-40 \%$ methanol/chloroform to obtain an oil. Ninhydrin spraying afforded a blue stain on TLC indicative of the primary amine compound 20. Yield 65\%, $R_{f}=0.51$ (10\% chloroform/methanol), $\mathrm{C}_{32} \mathrm{H}_{65} \mathrm{~N}_{5} \mathrm{O}_{4}$ (MW 583.5): MS (Positive/Negative ES) $\mathrm{m} / \mathrm{z}$ $590.3\left[\mathrm{M}+\mathrm{Li}\right.$ ], ${ }^{1} \mathrm{H}$ NMR $\left(400 \mathrm{MHz}, \mathrm{CDCl}_{3}, 20^{\circ} \mathrm{C}\right.$, TMS) $\delta 0.874\left(\mathrm{t}, 6 \mathrm{H}, \mathrm{CH}_{3}\right), 1.21-1.26$ (coherent peak, 32H, $8\left(\mathrm{CH}_{2}\right)_{2}$ ), $1.66\left(\mathrm{~m}, 4 \mathrm{H}, \mathrm{CH}_{2} \mathrm{CH}_{2} \mathrm{CO}\right.$ ), $2.18\left(\mathrm{~m}, 8 \mathrm{H}, \mathrm{CH}_{2} \mathrm{CO}, \mathrm{CH}_{2} \mathrm{NH}_{2}\right), 3.24$ - $3.74\left(\mathrm{~m}, 8 \mathrm{H}, \mathrm{CH}_{2} \mathrm{NHCO}\right.$, OCON $\left.\left(\mathrm{CH}_{2}\right)_{2}\right), 4.68$ (m, $\left.1 \mathrm{H},\left(\mathrm{CH}_{2}\right)_{2} \mathrm{CHOCO}\right), 6.26$ (t, $\left.2 \mathrm{H}, \mathrm{HNCO}\right)$.

The remaining saturated cationic lipid derivatives 21-23 were synthesized applying similar procedures 
(Scheme 2). All the compounds were obtained in the form of oil.

N, N'-dimyristoyl-1,3-diaminopropyl-2-[bis-(2-aminoethyl)] carbamate (21, MDVAD). Yield 50\%, $R_{f}=$ 0.50 (10\% chloroform/methanol), $\mathrm{C}_{36} \mathrm{H}_{73} \mathrm{~N}_{5} \mathrm{O}_{4}$ (MW 639): MS (Positive/Negative ES) $\mathrm{m} / \mathrm{z} 646.4[\mathrm{M}+\mathrm{Li}],{ }^{1} \mathrm{H}$ NMR $\left(400 \mathrm{MHz}, \mathrm{CDCl}_{3}, 20^{\circ} \mathrm{C}\right.$, TMS) $\delta 0.92\left(\mathrm{t}, 6 \mathrm{H}, \mathrm{CH}_{3}\right), 1.21-1.25$ (coherent peak, $40 \mathrm{H}, 10\left(\mathrm{CH}_{2}\right)_{2}$ ), $1.55(\mathrm{~m}$, $4 \mathrm{H}, \mathrm{CH}_{2} \mathrm{CH}_{2} \mathrm{CO}$ ), $2.18\left(\mathrm{~m}, 8 \mathrm{H}, \mathrm{CH}_{2} \mathrm{CO}, \mathrm{CH}_{2} \mathrm{NH}_{2}\right), 3.24$ - $3.69\left(\mathrm{~m}, 8 \mathrm{H}, \mathrm{CH}_{2} \mathrm{NHCO}, \mathrm{OCON}\left(\mathrm{CH}_{2}\right)_{2}\right), 4.76(\mathrm{~m}, 1 \mathrm{H}$, $\left.\left(\mathrm{CH}_{2}\right)_{2} \mathrm{CHOCO}\right), 6.36$ (m, 2H, HNCO).

N, N'-dipalmitoyl-1,3-diaminopropyl-2-[bis-(2-aminoethyl)] carbamate (22, PDVAD). Yield 58\%, $R_{f}=$ 0.49 (10\% chloroform/methanol), $\mathrm{C}_{40} \mathrm{H}_{81} \mathrm{~N}_{5} \mathrm{O}_{4}$ (MW 695): MS (Positive/Negative ES) m/z $702.4[\mathrm{M}+\mathrm{Li}] .{ }^{1} \mathrm{H}$ NMR (400 MHz, $\mathrm{CDCl}_{3}, 20^{\circ} \mathrm{C}$, TMS) $\delta 0.87-0.90\left(\mathrm{t}, 6 \mathrm{H}, \mathrm{CH}_{3}\right), 1.26-1.30$ (coherent peak, $48 \mathrm{H}, 12\left(\mathrm{CH}_{2}\right)_{2}$ ), 1.60 (m, 4H, $\left.\mathrm{CH}_{2} \mathrm{CH}_{2} \mathrm{CO}\right), 2.18\left(\mathrm{~m}, 8 \mathrm{H}, \mathrm{CH}_{2} \mathrm{CO}, \mathrm{CH}_{2} \mathrm{NH}_{2}\right), 3.30-3.70\left(\mathrm{~m}, 8 \mathrm{H}, \mathrm{CH}_{2} \mathrm{NHCO}, \mathrm{OCON}\left(\mathrm{CH}_{2}\right)_{2}\right)$, 4.74 (m, $\left.1 \mathrm{H},\left(\mathrm{CH}_{2}\right)_{2} \mathrm{CHOCO}\right), 6.42$ (m, 2H, HNCO).

$\mathrm{N}$, N'-distearoyl-1,3-diaminopropyl-2-[bis-(aminoethyl)] carbamate (23, SDVAD). Yield 40\%, $R_{f}=0.45$ (10\% chloroform/methanol). $\mathrm{C}_{44} \mathrm{H}_{89} \mathrm{~N}_{5} \mathrm{O}_{4}$ (MW 751): MS (Positive/Negative ES) $\mathrm{m} / \mathrm{z} 758.5$ [M + Li]. ${ }^{1} \mathrm{H}$ NMR (400 MHz, $\mathrm{CDCl}_{3}, 20^{\circ} \mathrm{C}$, TMS) $\delta 0.84\left(\mathrm{t}, 6 \mathrm{H}, \mathrm{CH}_{3}\right), 1.21-1.25$ (coherent peak, $56 \mathrm{H}, 14\left(\mathrm{CH}_{2}\right)_{2}$ ), 1.56 (m, 4H, $\mathrm{CH}_{2} \mathrm{CH}_{2} \mathrm{CO}$ ), 2.19 (m, $\left.8 \mathrm{H}, \mathrm{CH}_{2} \mathrm{CO}, \mathrm{CH}_{2} \mathrm{NH}_{2}\right), 3.40$ - $3.74\left(\mathrm{~m}, 8 \mathrm{H}, \mathrm{CH}_{2} \mathrm{NHCO}, \mathrm{OCON}\left(\mathrm{CH}_{2}\right)_{2}\right), 4.75(\mathrm{~m}, 1 \mathrm{H}$, $\left.\left(\mathrm{CH}_{2}\right)_{2} \mathrm{CHOCO}\right), 6.22$ (m, 2H, HNCO).

N, N'-dioleoyl-1,3-diaminopropyl-2-[bis-(2-aminoethyl)] carbamate (24, ODVAD). Due to the presence of a double bond between $\mathrm{C}_{9}-\mathrm{C}_{10}$ acyl chains of the oleoyl derivative, the benzyl chloroformate (Cbz) group was deprotected using triethylsilane and palladium (II) chloride, as shown in Scheme 2 [12]. Briefly, dibenzyl \{[(N, N'-dioleoyl-1, 3-diaminopropyl-2-oxycarbonyl) imino] diethane-2, 1-diyl\} biscarbamate 19 (1.75 g, $2.13 \mathrm{mmol})$ was dissolved in anhydrous chloroform $(20 \mathrm{~mL})$ under dry nitrogen. Palladium chloride $(300 \mathrm{mg}, 1.7 \mathrm{mmol})$ was added after which triethysilane $(5.3 \mathrm{~mL}, 33.2 \mathrm{mmol})$ was carefully added followed by dropwise addition of triethylamine $(0.83 \mathrm{~mL}, 5.9 \mathrm{mmol})$. The reaction was refluxed for three hours and then "quenched" with saturated aqueous ammonium chloride solution. The solution was partitioned between chloroform and saturated sodium bicarbonate and the organic layer was washed several times with saturated brine. The organic phase was collected, dried with $\mathrm{MgSO}_{4}$ and concentrated under reduced pressure. The crude residue was chromatographed on silica gel to give a light yellowish oil compound 24 (0.42 g, 70\%). $R_{f}=0.53$ (10\% chloroform/methanol). $\mathrm{C}_{44} \mathrm{H}_{85} \mathrm{~N}_{5} \mathrm{O}_{4}$ (MW 747), MS (Positive/Negative ES) $\mathrm{m} / \mathrm{z} 754.177$ [M + Li] ${ }^{1} \mathrm{H}$ NMR $\left(400 \mathrm{MHz}, \mathrm{CDCl}_{3}, 20^{\circ} \mathrm{C}\right.$, TMS) $\delta 0.86\left(\mathrm{t}, 6 \mathrm{H}, \mathrm{CH}_{3}\right), 1.24-1.28$ (coherent peak, $\left.40 \mathrm{H}, 10\left(\mathrm{CH}_{2}\right)_{2}\right), 1.62\left(\mathrm{~m}, 4 \mathrm{H}, \mathrm{CH}_{2} \mathrm{CH}_{2} \mathrm{CO}\right.$,), 1.96 - 2.25 (m, $16 \mathrm{H}, \mathrm{CH}_{2} \mathrm{CH}=\mathrm{CHCH}_{2} ; \mathrm{CH}_{2} \mathrm{CO}, \mathrm{CH}_{2} \mathrm{NH}_{2}$ ), $3.20-3.54$ (m, 8H, $\left.\mathrm{CH}_{2} \mathrm{NHCO}, \mathrm{OCON}\left(\mathrm{CH}_{2}\right)_{2}\right), 4.75$ (m, $1 \mathrm{H}$, $\left.\left(\mathrm{CH}_{2}\right)_{2} \mathrm{CHOCO}\right), 5.30$ (m, 4H, CH=CH), 6.24 (m, 2H, HNCO).

\subsection{HPLC Assay}

The HPLC system consisted of waters 515 gradient pump, 717 plus autosampler, chromatography workstation and Applied Biosystems 785A programmable absorbance detector (Schering Corporation). The stationary phase consisted of a silica-based $\mathrm{C}_{18}$ column maintained at $37^{\circ} \mathrm{C}$. A binary solvent system, consisting of methanol:acetonitrile $(95: 5 \mathrm{v} / \mathrm{v})$ with $0.1 \%$ trifluoroacetic acid, was used at a gradient mode to elute $100 \mu \mathrm{g} / \mathrm{mL} \mathrm{sam}$ ple of cationic lipids. The flow rate was kept at $0.5 \mathrm{~mL} / \mathrm{min}$ and one major peak was observed at $\lambda_{\max }=290 \mathrm{~nm}$ for all the lipids derivatives, with retention times 6, 3.9, 7.5, 7.5 and 9.5 minutes for dilauroyl, dimyristoyl, dipalmitoyl, distearoyl and dioleoyl, respectively.

\subsection{Plasmid DNA}

Both Plasmid DNA vectors were amplified in DH5 $\alpha$ competent cells, purified and quantified as described elsewhere [13].

\subsection{Preparation of Liposomal Dispersions}

Cationic lipid derivatives were dissolved in chloroform at concentrations of $0.6 \mathrm{mM}$ in borosilicate glass tubes. The solvents were evaporated with dry nitrogen stream to produce thin lipid films and completely removed under a strong vacuum (2 - 3 hours). The lipid films were hydrated at $60^{\circ} \mathrm{C}$ by the addition of appropriate volume of $40 \mathrm{mM}$ Tris, $\mathrm{pH} 7.2$ with occasional vortexing for a period of about 40 minutes to allow for self-assembly of cationic lipid molecules. The hydrated lipids were briefly sonicated in order to form small size uniform dispersions. 


\subsection{Transfection and Cytotoxicity Assay (Lipofection)}

In vitro transfection studies were performed as described elsewhere [14]. The cytotoxicity of the cationic lipid derivatives was evaluated with a 3-(4, 5-dimethylthiazol-2-yl)-2,5-diphenyltetrazolium bromide (MTT) assay.

\subsection{Agarose Gel Electrophoresis}

The complexation potential of the cationic lipid derivatives with plasmid DNA was investigated by an ethidium bromide (EtBr) exclusion assay in agarose gel electrophoresis experiment. The apparatus was filled with approximately $18 \mathrm{~mL}$ of agarose solution $(0.4 \mathrm{~g}$ in $50 \mathrm{~mL}$ of a $16 \mathrm{mM}$ TAE buffer $\mathrm{pH}$ 7.2, $40 \mathrm{mM}$ Tris-acetate, 1.14 $\mathrm{mL}$ glacial acetic acid, $1.0 \mathrm{mM}$ EDTA) containing $0.8 \%$. EtBr, for visualization of plasmid DNA. DNA migration was facilitated using an applied voltage of $5 \mathrm{~V}$ per centimeter for 30 minutes.

Lipoplexes were prepared in microcentrifuge tubes by addition of cationic lipids to $0.2 \mu \mathrm{g}$ of DNA, to attain charge ratios of $0.5: 1,1: 1,2: 1,4: 1,6: 1$ and $8: 1$. Lipoplexes were centrifuged at room temperature for 10 seconds at a speed of 15,000 rpm and allowed to stand at room temperature for 30 minutes. Prior to loading each sample into the wells of each gel, $1 \mu \mathrm{L}$ of a $0.25 \%$ bromophenol solution $(30.0 \%$ glycerol, $0.25 \%$ bromophenol blue, $0.25 \%$ xylene cyanol FF) was added to each sample. As a negative control, naked DNA was added to each gel in the outer lanes. After a 30 minute period the gel was viewed with a Densitometer UV light source and photographed with a Gel logic 200 imaging system (Eastman Kodak Company, New Haven, CT).

\subsection{Photon Correlation Spectroscopy and Electrophoretic Mobility (Zeta Potential)}

Particle size and zeta potential of lipid dispersions were measured using the Malvern Zetasizer Nano system (Malvern Instruments, Inc., Southborough, MA) in $40 \mathrm{mM}$ tris buffer and SFM. Lipid dispersions of approximately $120 \mathrm{nmol}$ were added to cuvettes followed by the addition of $40 \mathrm{mM}$ Tris buffer $\mathrm{pH} 7.2$, to a final volume of $0.2 \mathrm{~mL}$. Plasmid DNA was later added at charge ratios comparable to those used in the transfection experiments. The ensuing mixtures were incubated at room temperature with continuous stirring for 10 minutes after which time, the scattered light intensity of each sample at right angle was measured at $23^{\circ} \mathrm{C}$. The reported hydrodynamic radii distributions were derived using the Zetasizer Nano system’s self-analyzing autocorrelation function. The zeta potential of the aqueous vesicles was determined with and without the integration of plasmid DNA in $40 \mathrm{mM}$ Tris buffer $\mathrm{pH}$ 7.2. After measuring the particle size distribution within each sample, $0.75 \mathrm{~mL}$ $(0.1 \mu \mathrm{mol})$ was pipetted out and placed in the Zetasizer's folded capillary cell for zeta-potential measurement. Data presented are the average zeta potential and standard deviation obtained by averaging data collected over 30 cycles.

\subsection{Ethidium Bromide Displacement Assay}

Plasmid DNA $(22.5 \mu \mathrm{g}, 68.2 \mathrm{nmol})$ and ethidium bromide $(0.8 \mu \mathrm{g}, 2 \mathrm{nmol})$ were added to a quartz cuvette and diluted to $3 \mathrm{~mL}$ with $40 \mathrm{mM}$ tris buffer $\mathrm{pH}$ 7.2. Cationic lipid liposomal dispersions prepared in the same buffer at $2 \mathrm{mM}$ concentration were added in aliquots to the DNA:EtBr intercalating complex. After stirring for 5 minutes at $23^{\circ} \mathrm{C}$, the fluorescence of ethidium bromide alone was recorded with a Cary Eclipse fluorescence spectrophotometer (Varian Inc., CA.) at an excitation wavelength of $515 \mathrm{~nm}$ (slit width $5 \mathrm{~nm}$ ) and an emission wavelength of 595 - $605 \mathrm{~nm}$ (slit width $2.5 \mathrm{~nm}$ ). A negative control lacking the fluorescence probe was run side by side to the original experiment to correct for light scattering effect. The fluorescence signal of a blank ethidium bromide solution was subtracted from all measurements and the fluorescence intensity obtained from the plasmid DNA solution containing ethidium bromide in the absence of lipid $\left(F_{o}\right)$ was assigned a value of 100 . The resulting fluorescence intensity after addition of the cationic lipid ( $\left.F_{\text {complex }}\right)$ was normalized using Equation (1).

$$
\% \text { Displacement }=\frac{F_{\text {complex }}}{F_{o}} \cdot 100
$$

\subsection{Fluorescence Polarizations Studies}

Fluorescence anisotropy of the cationic lipid dispersions was measured using a Cary Eclipse Spectrophotometer (Varian Inc., Victoria, Australia) equipped with motorized polarizer employing the method described elsewhere [15]. The slit width for both excitation and emission was $5 \mathrm{~nm}$. Samples of cationic lipids dispersions containing 
DPH (0.6 mM lipid, lipid:DPH molar ratio of 500:1) in a standard $1 \mathrm{~cm} \times 1 \mathrm{~cm}$ fluorescence cuvette were placed in a thermoelectric temperature-controlled four-window cuvette holder with a magnetic stirrer (temperature control precision of $\pm 0.02^{\circ} \mathrm{C}$ ) and illuminated with a beam at $351 \mathrm{~nm}$. The fluorescence intensities $\left(\lambda_{\max }=430 \mathrm{~nm}\right)$ of the emitted light polarized parallel $\left(I_{h}\right)$ and perpendicular $\left(I_{v}\right)$ to the excited light were recorded at different temperatures. Anisotropy values at each temperature were calculated using the equation $r=\frac{\mathrm{I} v-G \mathrm{I}_{h}}{\mathrm{I} v-2 G \mathrm{I}_{h}}$ rooted in the Eclipse software. The temperature of the circulating water bath was raised $1^{\circ} \mathrm{C}$ every 5 minutes, allowing for temperature to equilibrate. The anisotropy-temperature curves were fitted using the equation below:

$$
r=A-\frac{B}{1+e^{-C(T-D)}}
$$

where $A, B, C$ and $D$ are constant parameters to be determined. The parameter $D$ denotes the gel to liquid crystalline phase transition temperature, $T_{m}$. Nonlinear curve fitting was done as described elsewhere [15].

\section{Results and Discussion}

Novel N,N'-diacyl-1,3-diaminopropyl-2-carbamoyl cationic lipid derivatives containing a symmetric bis[(aminoethyl)]-amine polar head group at the 2-position and hydrophobic chains at the 1- and 3-positions were synthesized by acylation of the 1,3-diamino-2-propanol backbone with lauroyl, myristoyl, palmitoyl, stearoyl, and oleoyl acyl chlorides. Purification of the derivative was done on silica gel and RP-HPLC. Identification and purity of the target compounds 20, 21, 22, 23, and 24 was done by NMR and Elemental analysis.

\subsection{In Vitro Lipofection}

B16-F0 cells were transfected with cationic lipid/pEGFP-N1 and cationic lipid/ $\beta$-gal lipoplexes at $+/-$ charge ratios of 1:1, 2:1 and 4:1. As shown in Figure 1(a), MDVAD and ODVAD were the most active derivatives. For ODVAD, activity was lowest at 1:1 ratio of N/P, with appreciable activity at 2:1. LDVAD, PDVAD and SDVAD were completely inactive at all charge ratios. These three derivatives were also the most difficult to hydrate. Quantitatively, $\beta$-gal activity was assessed using ONPG assay as described elsewhere by Kearns and research group. MDVAD showed high activity at charge ratio 2:1 and both MDVAD and ODVAD derivatives showed similar $\beta$-gal activity at charge ratios 4:1 (Figure 1(b)). Lipoplexes were well tolerated with appreciable cell survival at all different charge ratios (Figure 1(c)). It is worth to mention, that in our hands, the transfection activity of MDVAD and ODVAD was superior to that of the commercially available lipid DOTAP.

\subsection{Agarose Gel Electrophoresis}

The ability of each of the cationic lipid derivatives to complex with plasmid DNA was determined with a gel retardation assay. Complexation was evaluated based on their ability to associate with plasmid DNA, neutralize its negative charges and inhibit its migration in an electrophoretic field on an agarose gel (Figure 2(a)). In $40 \mathrm{mM}$ tris buffer $\mathrm{pH} 7.2$ the dioleoyl derivative was able to fully complex with and retard pDNA at charge ratios 4:1, 6:1 and 8:1. Clearly, none of the other lipid derivatives, LDVAD, MDVAD, PDVAD and SDVAD were able to fully neutralize the plasmid DNA at charge ratios in the range used in the transfection experiments.

\subsection{Ethidium Bromide Displacement Assay}

A much more sensitive measure for the interaction of cationic lipids with plasmid DNA is the ethidium bromide displacement assay. In this experiment, plasmid DNA is first placed in $40 \mathrm{mM}$ Tris buffer $\mathrm{pH} 7.2$ with EtBr. The distinctive fluorescence enhancement of the intercalated $\mathrm{EtBr}$ in the DNA helix allows the precise spectrophotometric quantification of its elimination from the double helix of the plasmid DNA upon addition of cationic lipids in small aliquots. This is used to establish the exact charge ratio at which cationic lipids fully dislodge $\mathrm{EtBr}$ from plasmid DNA. The reduction in fluorescence observed was measured and a plot of the normalized displacement (Figure 2(b)) indicated that the dioleoyl derivative was able to associate approximately $60 \%$ of the initial concentration of DNA at a charge ratio of 2:1. This was in conformity with the agarose gel electrophoresis results which indicated that complete electrostatic interaction of plasmid DNA by the ODVAD occurred at charge ratios greater than 2. In contrast, LDVAD, PDVAD and SDVAD demonstrated low level of plasmid 


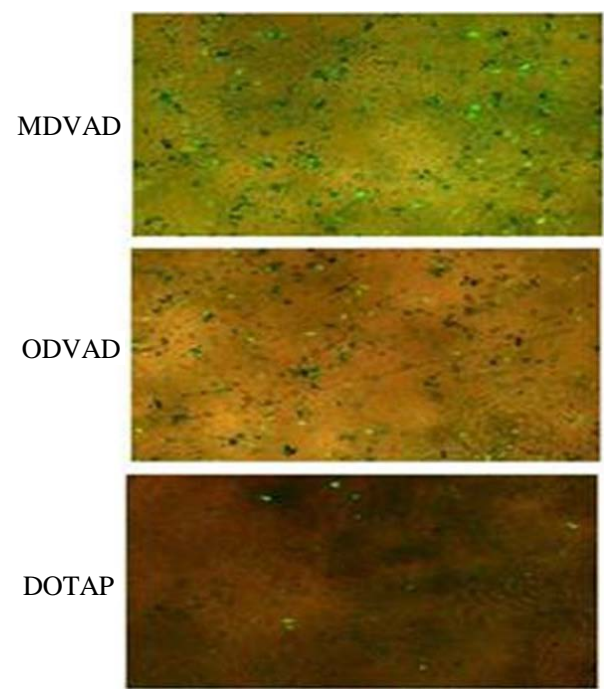

(a)

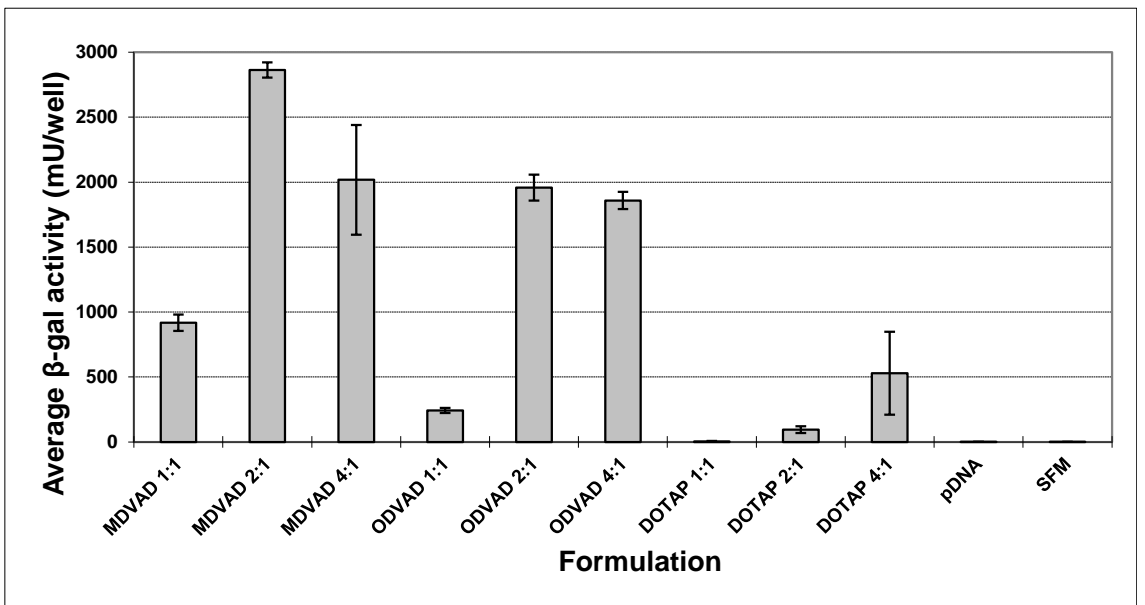

(b)

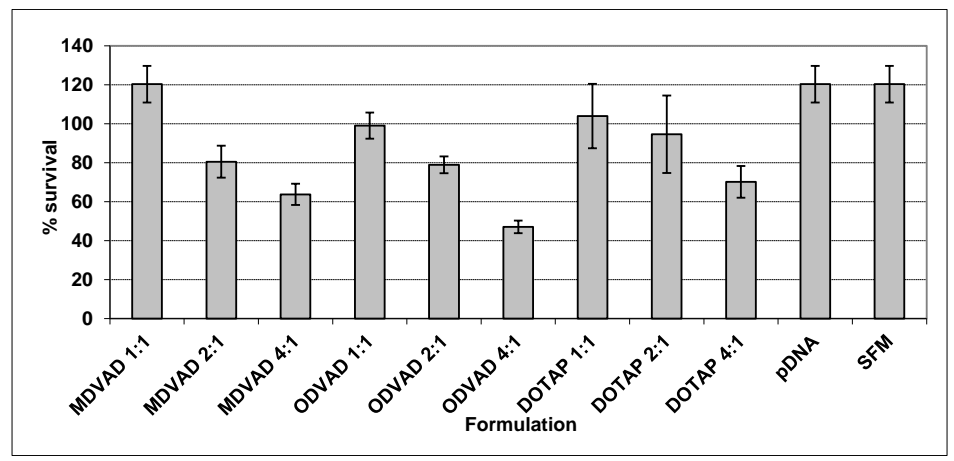

(c)

Figure 1. (a) Fluorescence of EGFP in B16F0 cells transfected with lipoplexes of MDVAD, ODVAD and DOTAP as a positive control at $+/-$ charge ratio of $2: 1$, in the absence of helper lipids. Panels represent fluorescence overlay images; (b) $\beta$-Gal gene expression in B16-F0 cell. The data shown represent the average of four wells treated at the same day. The experiment was repeated 4 times and day-to-day variation was found to be within one fold of the presented data; (c) Percentage survival of B16F0 mouse melanoma cells transfected with various formulations of cationic lipid derivatives. Data presented are the average of 3 wells treated the same day. 


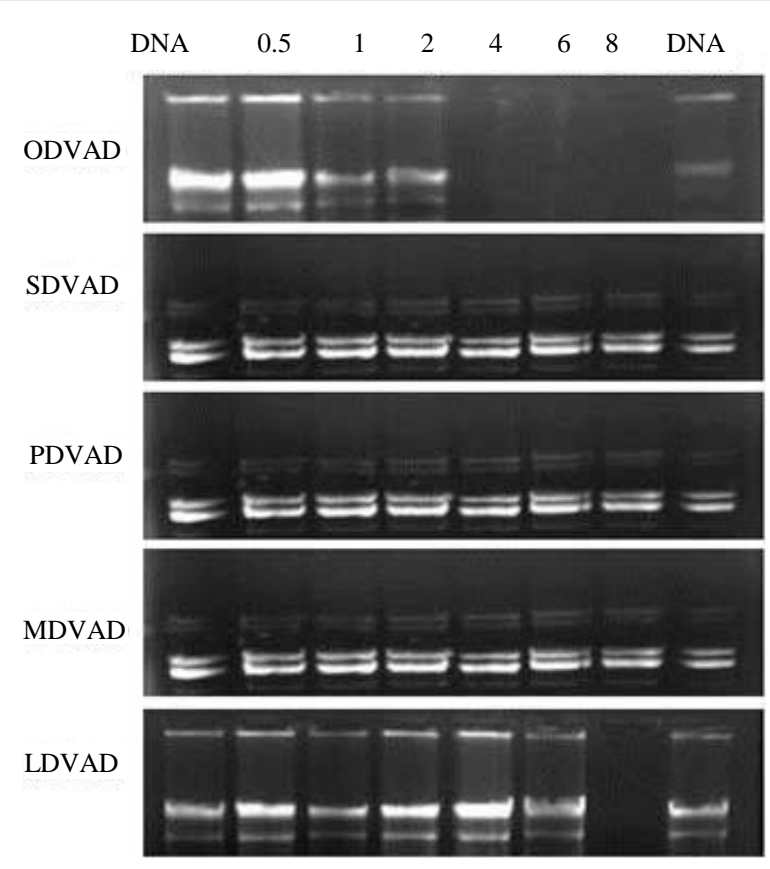

(a)

-LDVAD $\square$ MDVAD $\triangle$ PDVAD XSDVAD $*$ ODVAD •DOTAP

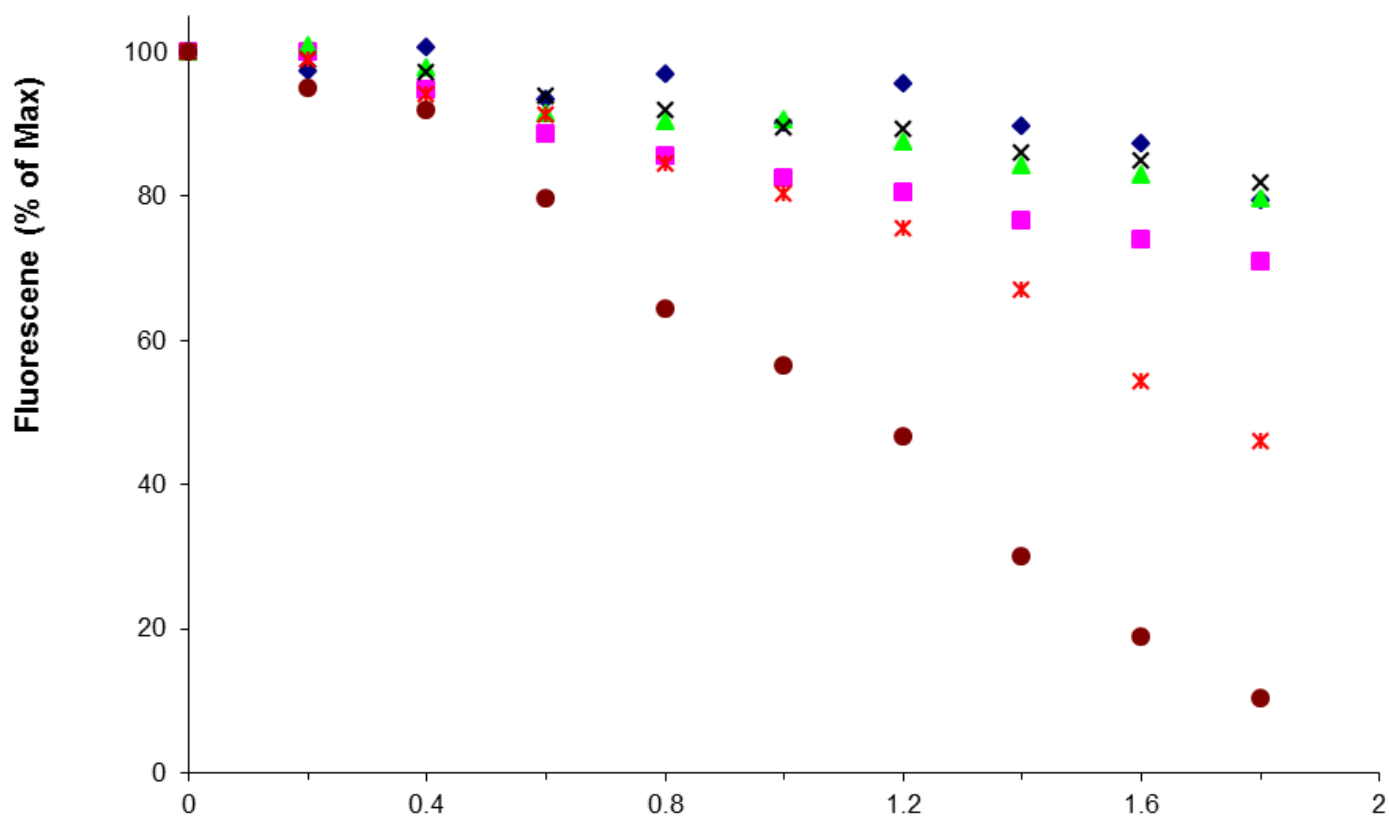

Charge Ratio (+/-)

(b)

Figure 2. (a) Gel retardation assay of lipoplexes in the absence of helper lipids in $40 \mathrm{mM}$ tris buffer $\mathrm{pH} 7.2$. for ODVAD, SDVAD, PDVAD, MDVAD and LDVAD; (b) Representative titration of plasmid DNA containing intercalated EtBr with cationic lipids ODVAD, SDVAD, PDVAD, MDVAD and LDVAD. The assay measures the percentage of $\mathrm{EtBr}$ displaced as a function of increased charge ratio of lipoplexes in $40 \mathrm{mM}$ tris buffer $\mathrm{pH} 7.2$. 
DNA association (maximum of 18\%) at all charge ratios. MDVAD on the other hand, appeared to displace EtBr from the pDNA with the same efficiency as ODVAD up to charge ratio 1:1, but as the charge increased, there was an accompanying increase in DNA interaction up to a maximum of approximately $25 \%$.

\subsection{Photon Correlation Spectroscopy and Electrophoretic Mobility}

Each of the cationic lipid derivatives was hydrated in tris buffer $\mathrm{pH} 7.2$ resulting in the formation of colloidal dispersions. The dispersions formed by the dioleoyl derivative had an average particle size of about $0.2 \mu \mathrm{m}$ whereas the sizes of the liposomes determined for the other four lipid derivatives, LDVAD, MDVAD, PDVAD and SDVAD, were $0.5 \mu \mathrm{m}$ or greater (Table 1). Values of polydispersity index greater than 0.2 suggest heterogeneous populations. Only the lipid dispersions of ODVAD were uniform with respect to the size of the particles. Therefore, lipid dispersions made of saturated cationic lipids were a mixture of small and bigger particles. Upon addition of DNA, the hydrodynamic diameter of the lipoplexes comprising the saturated cationic lipid derivatives except of the PDVAD grew bigger with increasing charge ratio. Lipoplexes composed of PDVAD became somewhat smaller upon addition of plasmid DNA, but the big PI value suggests that the population was heterogeneous in size. Lipoplex prepared from the ODVAD exhibited an increased particle size as compared to the lipid dispersion in the absence of plasmid DNA. At charge ratio 1:1 the particle population appear to be heterogeneous, but homogeneity was reestablished at increasing proportions of the cationic lipid. The results of the hydrodynamic diameter distribution suggest that, aside from ODVAD, all other lipid dispersions were a mixture of bigger and smaller aggregates of reduced capacity to interact and condense the plasmid DNA in a uniform mode.

All lipid dispersions exhibited positive zeta potential in buffer solution pH 7.2 (Table 1), suggesting that the primary amine polar head of all five cationic lipids was hydrated well, developing a positive charge on the water interphase. At a lipid:DNA ratio of 1:1, the zeta potential for the ODVAD derivative maintained a positive zeta potential, albeit its particle size and size heterogeneity increased. Lipoplexes of all the other four derivatives, LDVAD, MDVAD, PDVAD and SDVAD, showed negative zeta potential values. Increasing the amount of cationic lipid of the saturated cationic derivatives failed to increase the zeta potential, suggesting that contrary to the unsaturated cationic derivative ODVAD, the saturated derivatives failed to fully interact and neutralize the negative charges present on the phosphodiester bonds of the plasmid DNA. Contrary to that, increasing the amount of ODVAD added to plasmid DNA, resulted in increasing the positive value of zeta potential and simultaneously improving the homogeneity of the particle population with respect to its size. This behavior is reflective of the electrostatic stabilization imposed by the excess cationic lipid enveloping the plasmid DNA. A whole different picture can be conceived with the saturated cationic derivatives. The fact that upon addition of plasmid DNA, the positive zeta potential of the lipid dispersions is acquiring a negative value, suggests that plasmid DNA is wrapped predominantly outside of the particles. We know this because plasmid DNA, at the concentration added, by itself (in the absence of cationic lipids) failed to scatter any light and register a zeta potential. It is possible that the cohesive interactions among saturated lipid derivatives are too strong to allow reorganization and wrapping around DNA. The situation is further deteriorating with time, because the plasmid DNA anchored on the surface of lipid vesicles will cause cross complexation with bald areas of other cationic particles and recruitment of more vesicles, thus causing the formation of bigger aggregates. These results along with the results of the particle size analysis confirmed the inability of the cationic lipids with the saturated acyl chains to electrostatically interact fully and effectively associated with the plasmid DNA.

\subsection{Fluorescence Anisotropy Studies}

As indicated in Figure 3, the type and length of the acyl chain influenced the dependence of fluorescence anisotropy of the cationic lipid assemblies on temperature. All the cationic lipids exhibited one or more inflections in their profile with the exception of the dilauroyl and dioleoyl derivatives, suggesting that the gel-to-liquid crystalline phase transitions were below $10^{\circ} \mathrm{C}$. The gel-to-liquid phase transition temperatures for MDVAD, PDVAD and SDVAD were determined to be $27.5^{\circ} \mathrm{C}, 32.5^{\circ} \mathrm{C}$ and $39^{\circ} \mathrm{C}$, respectively (Table 2). The fluorescence anisotropy data verified that all of the derivatives except SDVAD, existed in a fluid state at physiological temperature. Naturally, as the length of the acyl chain increases, the gel-to-liquid crystalline phase transition temperature increases as well. 
Table 1. Particle size and zeta potential measurements of cationic lipid dispersions and lipoplexes, at various charge ratios, in $40 \mathrm{mM}$ tris solution $\mathrm{pH}$ 7.2. Results shown represent the mean diameter of two separate experiments.

\begin{tabular}{|c|c|c|c|c|c|}
\hline & & $\mathrm{D}(\mathrm{nm})$ & $\mathrm{PI}^{\mathrm{a}}$ & ${ }^{\mathrm{b}} \mathrm{ZP}(\mathrm{mV})$ & ${ }^{\mathrm{c}} \mathrm{SD}$ \\
\hline \multirow[t]{4}{*}{ LDVAD } & Lipid dispersion & 481 & 0.4 & +47 & 4.0 \\
\hline & Lipoplexes (1:1) & 981 & 0.6 & -29 & 3.8 \\
\hline & Lipoplexes (2:1) & 791 & 0.7 & -31 & 6.4 \\
\hline & Lipoplexes (4:1) & 644 & 0.5 & -27 & 8.2 \\
\hline \multirow[t]{4}{*}{ MDVAD } & Lipid dispersion & 587 & 0.5 & +44 & 3.2 \\
\hline & Lipoplexes (1:1) & 817 & 0.6 & -30 & 20 \\
\hline & Lipoplexes (2:1) & 664 & 0.7 & -27 & 12 \\
\hline & Lipoplexes (4:1) & 840 & 0.6 & -29 & 9.4 \\
\hline \multirow[t]{4}{*}{ PDVAD } & Lipid dispersion & 986 & 0.6 & +46 & 3.0 \\
\hline & Lipoplexes (1:1) & 533 & 0.6 & -25 & 13 \\
\hline & Lipoplexes (2:1) & 527 & 0.6 & -21 & 8.3 \\
\hline & Lipoplexes (4:1) & 599 & 0.5 & -22 & 6.1 \\
\hline \multirow[t]{4}{*}{ SDVAD } & Lipid dispersion & 1483 & 0.4 & +44 & 3.0 \\
\hline & Lipoplexes (1:1) & 2990 & 1 & -29 & 9.8 \\
\hline & Lipoplexes (2:1) & 809 & 0.6 & -20 & 10 \\
\hline & Lipoplexes (4:1) & 1657 & 1 & -21 & 8.4 \\
\hline \multirow[t]{4}{*}{ ODVAD } & Lipid dispersion & 192 & 0.2 & +49 & 4.2 \\
\hline & Lipoplexes (1:1) & 547 & 0.6 & +1.7 & 3.4 \\
\hline & Lipoplexes (2:1) & 552 & 0.3 & +5.4 & 3.5 \\
\hline & Lipoplexes (4:1) & 521 & 0.09 & +18 & 3.5 \\
\hline
\end{tabular}

${ }^{\mathrm{a}} \mathrm{PI}$ denotes polydispersity index; ${ }^{\mathrm{b}} \mathrm{ZP}$ denotes zeta potential; ${ }^{\mathrm{c}} \mathrm{SD}$ denotes standard deviation.

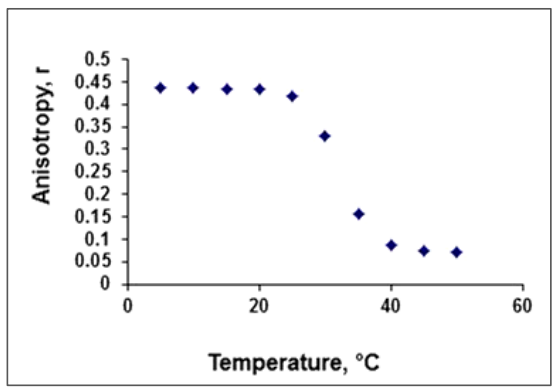

(a)

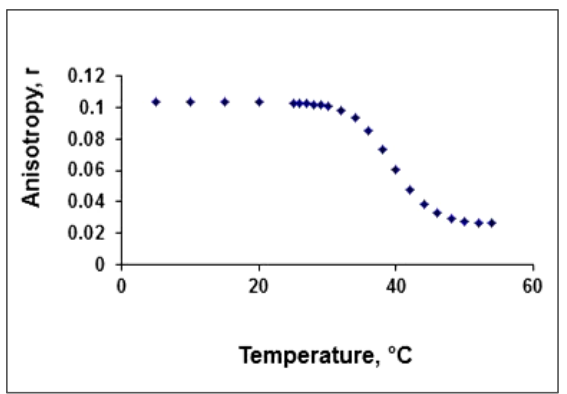

(c)

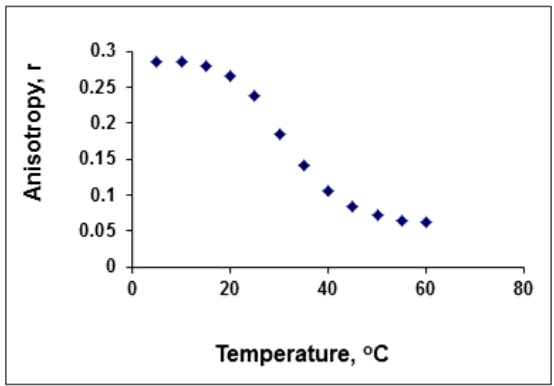

(b)

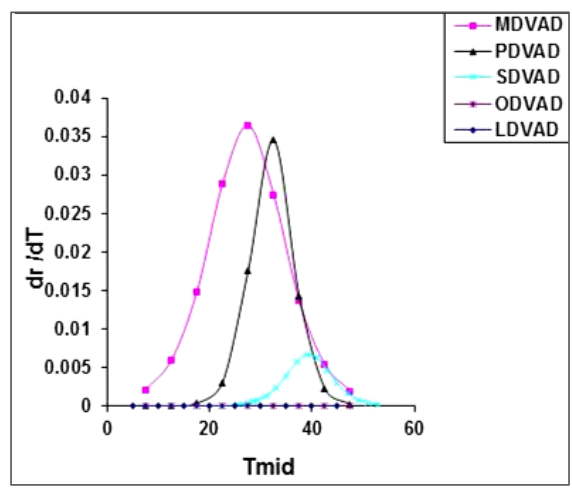

(d)

Figure 3. Representative fluorescence anisotropy (r) against temperature plots of bivalent cationic lipid dispersions at pH 7.2. A. PDVAD B. MDVAD C. SDVAD D. First derivative of fluorescence anisotropy (r) against temperature plots for the bivalent cationic lipid dispersions at pH 7.2. 
Table 2. Phase transition parameters of bivalent amine cationic lipids as determined by fluorescence anisotropy.

\begin{tabular}{cccc}
\hline Lipid & $\mathrm{T}_{\mathrm{m}}\left({ }^{\circ} \mathrm{C}\right)$ & Coefficient of determination $^{\mathrm{a}}$ & $\mathrm{T}_{\text {onset }}\left({ }^{\circ} \mathrm{C}\right)^{\mathrm{b}}$ \\
\hline LDVAD & $<10$ & $\mathrm{ND}$ & $<10$ \\
MDVAD & 27.50 & 0.9889 & 29.5 \\
PDVAD & 32.50 & 0.9942 & 33.5 \\
SDVAD & 39.00 & 0.9834 & 43.0 \\
OVDAD & $<10$ & ND & $<10$ \\
\hline
\end{tabular}

${ }^{\mathrm{a}}$ Goodness of fit statistics for $\mathrm{T}_{\mathrm{m}}$ were assessed with $95 \%$ confidence interval; ${ }^{\mathrm{b}}$ Onset transition temperature values were determined from Figures 3(a)-(c) by extrapolation.

\section{Conclusion}

We have identified in the past that a gel-to-liquid crystalline phase transition temperature below $37^{\circ} \mathrm{C}$, is a necessary condition for transfection activity to take place in in vitro cell culture and in the absence of other helper lipids. This increased fluidity at physiological temperatures, is the single property that we have repeatedly and consistently identified as the essential characteristic of transfection potent cationic lipids [16] [17]. The current study reaches the same conclusion. To be more specific, SDVAD does not mediate transfection and its gel-to-liquid crystalline phase transition temperature is above $37^{\circ} \mathrm{C}$. MDVAD on the other hand, is fluid at physiological temperature and although it doesn't condense the plasmid DNA efficiently to a small particle size, the loosely associated lipoplexes are able to mediate high levels of transfection activity in the absence of helper lipids.

\section{Acknowledgments}

All materials and equipment used in this study were supported by a grant from the National Institutes of Health, EB004863, USA.

Molecular mass analysis (Hunter College Mass Spectrometry laboratory, NY USA).

\section{References}

[1] Patil, P.M., Chaudhari, P.D., Megha, S. and Duragkar, N.J. (2012) Review Article on Gene Therapy. International Journal of Genetics, 4, 74-79.

[2] Mahato, R.I., Rolland, A. and Tomlinson, E. (1997) Cationic Lipid-Based Gene Delivery Systems: Pharmaceutical Perspectives. Pharmaceutical Research, 14, 853-859. http://dx.doi.org/10.1023/A:1012187414126

[3] Lee, E.R., Marshall, J., Siegel, C.S., Jiang, C., Yew, N.S., Nichols, M.R., Nietupski, J.B., Ziegler, R.J., Lane, M.B., Wang, K.X., Wan, N.C., Scheule, R.K., Harris, D.J., Smith, A.E. and Cheng, S.H. (1996) Detailed Analysis of Structures and Formulations of Cationic Lipids for Efficient Gene Transfer to the Lung. Human Gene Therapy, 7, 17011717. http://dx.doi.org/10.1089/hum.1996.7.14-1701

[4] Felgner, J.H., Kumar, R., Sridhar, C.N., Wheeler, C.J., Tsai, Y.J., Border, R., Ramsey, P., Martin, M. and Felgner, P.L. (1994) Enhanced Gene Delivery and Mechanism Studies with a Novel Series of Cationic Lipid Formulations. Journal of Biological Chemistry, 269, 2550-2561.

[5] Ajit. S.N., Thoma, L., Miller, D.D. and Mahato, R.I. (2005) Cationic Lipids with Increased DNA Binding Affinity for Nonviral Gene Transfer in Dividing and Nondividing Cells. Bioconjugate Chemistry, 16, 156-168. http://dx.doi.org/10.1021/bc049818q

[6] Felgner, P.L., Gadek, T.R., Holm, M., Roman, R., Chan, H.W., Wenz, M., Northrop, J.P., Ringold, G.M. and Danielsen, M. (1987) Lipofection: A Highly Efficient, Lipidmediated DNA-Transfection Procedure. Proceedings of the National Academy of Sciences of the United States of America, 84, 7413-7417. http://dx.doi.org/10.1073/pnas.84.21.7413

[7] Gao, X. and Huang, L. (1991) A Novel Cationic Liposome Reagent for Efficient Transfection of Mammalian Cells. Biochemical and Biophysical Research Communications, 179, 280-285. http://dx.doi.org/10.1016/0006-291X(91)91366-K

[8] Behr, J.P., Demeneix, B., Loeffler, J.P. and Perez-Mutul, J. (1989) Efficient Gene Transfer into Mammalian Primary Endocrine Cells with Lipopolyamine-Coated DNA. Proceedings of the National Academy of Sciences of the United 
States of America, 86, 6982-6986. http://dx.doi.org/10.1073/pnas.86.18.6982

[9] Edelstein, M.L., Abedi, M.R., Wixon, J. and Edelstein, R.M. (2004) Gene Therapy Clinical Trials Worldwide 19892004-An Overview. Journal of Gene Medicine, 6, 597-602. http://dx.doi.org/10.1002/jgm.619

[10] Sheikh, M., Feig, J., Gee, B. and Savva, M. (2003) In Vitro Lipofection with Novel Series of Symmetric 1,3-Diakylamidopropane-Based Cationic Surfactants Containing Single Primary and Tertiary Amine Polar Head Groups. Chemistry and Physics of Lipids, 124, 49-61. http://dx.doi.org/10.1016/S0009-3084(03)00033-1

[11] Savva, M., Aljaberi, A., Feig, J. and Stolz, D.B. (2005) Correlation of the Physicochemical Properties of Symmetric 1,3-dialkoylamidopropane-Based Cationic Lipids Containing Single Primary and Tertiary Amine Polar Head Groups with in Vitro Transfection Activity. Colloids and Surfaces B: Biointerfaces, 43, 43-56. http://dx.doi.org/10.1016/j.colsurfb.2005.03.008

[12] Sakaitani, M. and Ohfune, Y. (1990) Syntheses and Reactions of Silyl Carbamates. 1. Chemoselective Transformation of Amino Protecting Groups via Tert-Butyldimethylsilyl Carbamates. The Journal of Organic Chemistry, 55, 870-876. http://dx.doi.org/10.1021/jo00290a015

[13] Kearns, M., Donkor, A.-M. and Savva, M. (2007) Structure-Transfection Activity Studies of Novel Cholesterol Based Amphiphiles. Molecular Pharmaceutics, 5, 128-139. http://dx.doi.org/10.1021/mp700131c

[14] Spelios, M. and Savva, M. (2007) Novel N,N'-diacyl-1,3-diaminopropyl-2-carbamoyl Bivalent Cationic Lipids for Gene Delivery-Synthesis, in Vitro Transfection Activity and Physicochemical Characterization. FEBS Journal, 275, 148-162. http://dx.doi.org/10.1111/j.1742-4658.2007.06185.X

[15] Savva, M., Chen, P., Aljaberi, A., Selvi, B. and Spelios, M. (2005) In Vitro Lipofection with Novel Asymmetric Series of 1,2-dialkoylamidopropane-Based Cytofectins Containing Single Symmetric Bis-(2-dimethylaminoethane) Polar Head Groups. Bioconjugate Chemistry, 16, 1411-1422. http://dx.doi.org/10.1021/bc050138c

[16] Aljaberi, A. and Savva, M. (2005) Synthesis, in Vitro Transfection Activity and Physicochemical Characterization of Novel $N, N$ '-diacyl-1,2-diaminopropyl-3-carbamoyl-(dimethylaminoethane) Amphiphilic Derivatives. Chemistry and Physics of Lipids, 133, 135-149. http://dx.doi.org/10.1016/j.chemphyslip.2004.09.017

[17] Aljaberi, A., Spelios, M., Kearns, M., Selvi, B. and Savva, M. (2007) Physicochemical Properties Affecting Lipofection Potency of a New Series of 1,2-dialkoylamidopropane-Based Cationic Lipids. Colloids and Surfaces B: Biointerfaces, 57, 108-117. http://dx.doi.org/10.1016/j.colsurfb.2007.01.012

\section{Abbreviations}

DOTAP: 1, 2-dioleoyl-3-trimethylammonium-propane;

EtBr: ethidium bromide;

LDVAD: N,N'-dilauroyl-1,3-diaminopropyl-2-carbamoyl-bis[(aminoethyl)]-amine; other cationic lipids follow the same nomenclature as LDVAD but with different acyl chains;

MDVAD: dimyristoyl derivative;

PDVAD: dipalmitoyl derivative;

SDVAD: distearoyl derivative;

ODVAD: dioleoyl derivative;

N/P: Nitrogen/Phosphate;

$\mathrm{T}_{\mathrm{m}}$ : maximum transition temperature;

ONPG: ortho-nitrophenyl-beta-D-galactoside. 
Scientific Research Publishing (SCIRP) is one of the largest Open Access journal publishers. It is currently publishing more than 200 open access, online, peer-reviewed journals covering a wide range of academic disciplines. SCIRP serves the worldwide academic communities and contributes to the progress and application of science with its publication.

Other selected journals from SCIRP are listed as below. Submit your manuscript to us via either submit@scirp.org or Online Submission Portal.
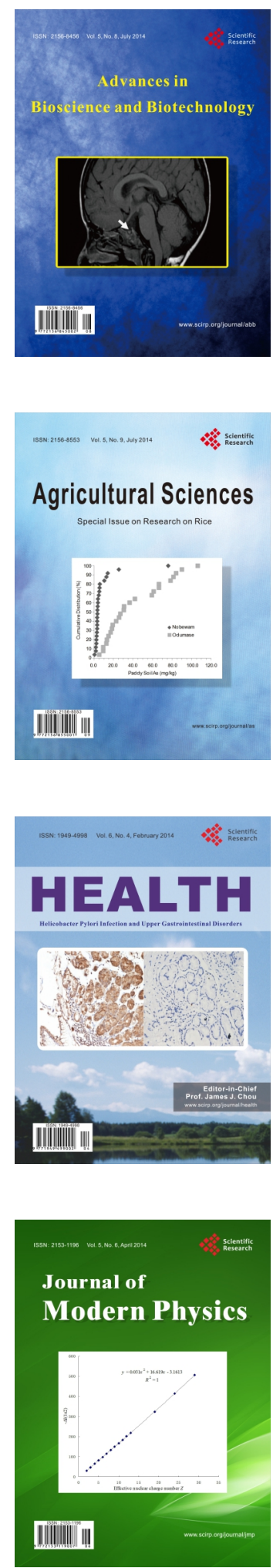
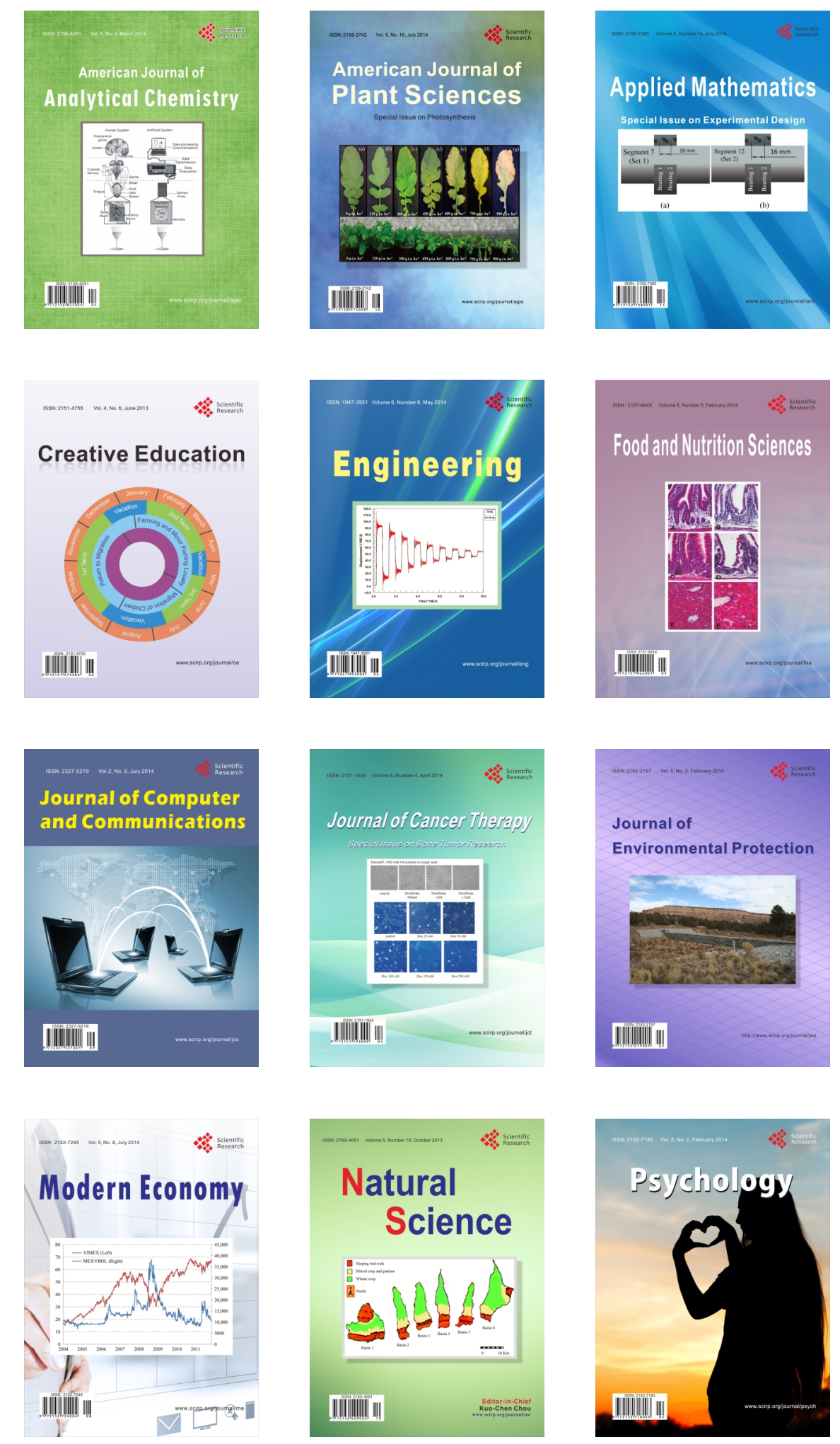